\title{
Pembuatan Alat Impedance Tube dan Simulasi Pengukuran Koefisien Serap Menggunakan Software MATLAB R2013A
}

Azis Eko Prakoso ${ }^{1 *}$, Alex Farachniamala ${ }^{1}$, Pitri Andayani ${ }^{1}$, Opta Muzaki Effendi ${ }^{1}$, Mohtar Yunianto ${ }^{1}$ dan Malinda Sabrina ${ }^{2}$

${ }^{1}$ Program Studi Fisika, Fakultas Matematika \& IPA, Universitas Sebelas Maret, Surakarta ${ }^{2}$ Grup Riset Aero Akustik BBTA3 BPPT Serpong Tangerang Selatan

*Email: azisekoprakoso@gmail.com

\begin{abstract}
Abstrak
Telah dilakukan pembuatan alat impedance tube sesuai dengan standar ISO 10534-2: 1998 [2] yaitu dimensi tabung $10 \mathrm{~cm}$, ketebalan tabung $5 \mathrm{~mm}$, jarak antara sumber suara dengan microphone terdekat $70 \mathrm{~cm}$, jarak antara sampel dengan microphone terdekat $21 \mathrm{~cm}$, jarak antar microphone $9 \mathrm{~cm}$, frekuensi batas atas pengukuran $2000 \mathrm{~Hz}$ dan frekuensi batas bawah pengukuran $125 \mathrm{~Hz}$. Pada penelitian ini digunakan metode impedance tube 2 microphone untuk melakukan pengukuran koefisien serap material. Prinsip kerja dari metode ini adalah dengan membandingkan hasil pengukuran tekanan pada kedua microphone yang kemudian digunakan untuk melakukan perhitungan fungsi transfer. Setelah fungsi transfer diketahui nilainya, maka dilakukan perhitungan nilai koefisien refleksi dan nilai koefisien serap. Simulasi perhitungan koefisien absorbsi alat impedance tube menggunakan software Matlab R2013a.
\end{abstract}

Kata kunci: impedance tube, koefisien serap, Matlab

\section{Pendahuluan}

Penyerapan bunyi adalah proses perubahan energi bunyi ketika bunyi menumbuk suatu material menjadi bentuk energi lain yang biasanya berupa energi panas [1]. Jenis material penyerap bunyi antara lain: bahan berpori, resonator rongga (Helmholtz), panel absorber, dan lain lain. Pengelompokan dari jenis material penyerap bunyi didasarkan pada proses perubahan energi suara yang menumbuk permukaan bahan menjadi energi panas ${ }^{[3]}$.

Koefiesien absorbsi adalah nilai dari penyerapan energi bunyi dari material saat bunyi datang menumbuk material. Koefisien ini dilambangkan dalam huruf Greek $\alpha .{ }^{[1]}$. Koefisien absorbsi bunyi $(\alpha)$ memiliki nilai diantara 0 sampai dengan 1 . Nilai koefisien absorbsi 0 menyatakan material tidak menyerap bunyi dan nilai koefisien serapan 1 menyatakan material menyerap bunyi dengan sempurna ${ }^{[4]}$.

Proses pembuatan impedance tube memiliki standar ISO 10534-2: 1998 [2] yang menetapkan batas atas frekuensi untuk tabung impedansi melingkar adalah $f u<0.58 \frac{c 0}{d}$ dimana c0 adalah kecepatan suara di udara dan $\mathrm{d}$ adalah diameter dalam tabung.

Frekuensi atas juga dibatasi oleh jarak antara titik pengukuran sepanjang tabung, karena salah satu harus memastikan perbedaan fase tertentu setidaknya setengah panjang gelombang, $f u<0.45 \frac{c 0}{s}$ dimana s adalah jarak antara posisi microphone, sering dilambangkan sebagai jarak microphone. Frekuensi terendah yang tersedia terbatas pada panjang gelombang yang begitu lama bahwa tekanan pada mikrofon yang sangat mirip dan tidak ada perbedaan tekanan yang jelas dapat diukur, $f l<0.05 \frac{c 0}{s}$. ${ }^{[5]}$.

Matlab pertama kali dikenalkan oleh University of New Mexico dan University of Stanford pada tahun 1970 yang merupakan singkatan dari Matrix Laboratory. Pada awalnya software Matlab digunakan untuk menganalisa teori tentang matriks, aljabar liner, dan keperluan analisis numerik ${ }^{[2] .}$ Software Matlab dipilih untuk simulasi ini karena dapat menghitung eksponen bilangan imajiner dan dibuat perulangan tanpa harus menginput berulang kali.

Tujuan dari penulisan ini adalah untuk mengetahui standar pembuatan alat impedance tube, cara simulasi perhitungan koefisien serap menggunakan Matlab R2013a

\section{Metodologi \\ 2.1 Prosedur Penelitian}

Prosedur penelitian ini dimulai dengan kajian tentang impedance tube. Pada penelitian kali ini dipilih acrilic sebagai bahan untuk membuat impedance tube. Pemilihan acrilic ini dikarenakan acrilic lebih rigid sehingga diharapkan tidak banyak bunyi yang bocor keluar dari tabung.

Tabung acliric yang digunakan memiliki diameter dalam tabung $10 \mathrm{~cm}$ dan ketebalan acrlic $5 \mathrm{~mm}$. Rubber seal yang digunakan berdiameter dalam $1,27 \mathrm{~cm}$ dan diameter luar 
1,7 cm. Diameter lubang acrilic sebesar 1,7 cm sesuai dengan diameter luar rubber seal.

Rancang bangun impadance tube pada penelitian ini berpedoman pada standar ISO 10534-2: 1998 dengan definisi sebagai berikut :

- Diameter tabung $=10 \mathrm{~cm}$

- Ketebalan tabung = 5\% x d = 5 mm

- Jarak antara sumber suara dengan mic terdekat $=70 \mathrm{~cm}$

- Jarak antara sampel dengan mic terdekat = $21 \mathrm{~cm}$

- Jarak antar mic $=9 \mathrm{~cm}$

- Frekuensi batas atas $=1995,2 \mathrm{~Hz}$ batas bawah $=38,22 \mathrm{~Hz}$

Sampel yang digunakan adalah styrofoam dengan ketebalan $0.8 \mathrm{~cm}$. Pemotongan sampel menggunakan cutter yang sebelumnya telah di ukur sesuai dengan diameter dalam tabung.

Susunan alat untuk penelitian ini adalah tabung impedansi dibuat menjadi 3 bagian yaitu tabung utama, tabung sumber suara dan tabung tempat sampel. Pada tabung sumber suara di rangkai woofer 3 inchi dengan pembangkit amplifier. Pembangkit ampflier ini dinyalakan dengan aki DC 12 Volt dan diberi input suara dari function generator. Pada tabung utama, 2 buah mic freefield $1 / 2$ inchi dimasukkan kedalam rubber seal setara dengan muka tabung bagian dalam. Sedangkan pada tabung tempat sampel terdiri dari sampel, dan kayu sebagai piston pendorong sekaligus penahan sampel.

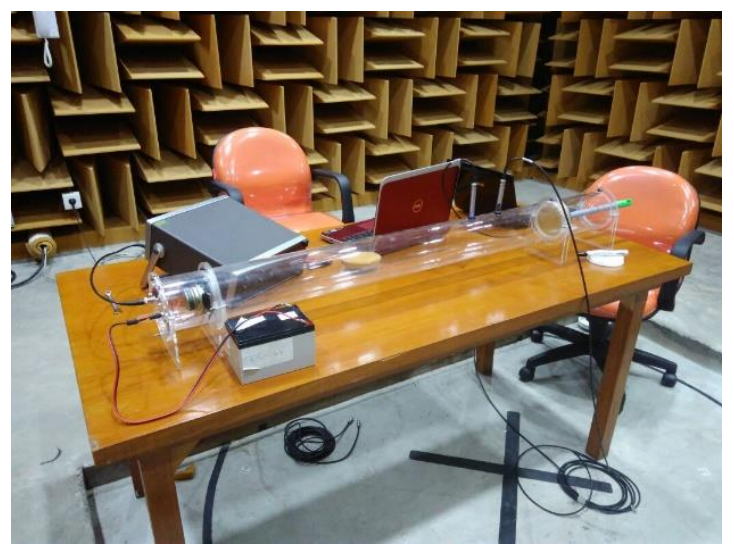

Gambar 1. Susunan alat impedance tube

\subsection{Teknik Pengambilan Data}

Pengambilan data dilakukan dengan cara memvariasi frekuensi dan pada function generator. Skala putar frekuensi pada function generator divariasi pada skala $125 \mathrm{~Hz}, 250 \mathrm{~Hz}$, $500 \mathrm{~Hz}, 1000 \mathrm{~Hz}$, dan $2000 \mathrm{~Hz}$. Sampel diuji dengan menggunakan metode transfer function yaitu dengan membandingkan hasil pengukuran tekanan suara pada 2 freefield microphone.
Masing-masing dari freefield microphone akan mengukur tekanan yang di set dalam satuan Pascal. Nilai transfer function diperoleh dari tekanan pada microphone kedua (yang dekat dengan sampel) dibagi dengan tekanan pada microphone pertama (yang jauh dari sampel).

\subsection{Simulasi perhitungan pada Matlab}

Langkah awal untuk melakukan simulasi nilai koefisien serap material adalah dengan mendeklarasikan terlebih dahulu masingmasing nilai jarak microphone 1 dan microphone 2 dengan sampel. Kemudian deklarasikan pula jarak antar microphone.

Langkah selanjutnya adalah memasukkan nilai frekuensi dan nilai tekanan yang diukur oleh tiap microphone (yang dilambangkan P1 dan P2 kemudian program mulai menghitung nilai fungsi transfer $(H)$, angka gelombang (k), koefisien refleksi (R), dan koefisien serap (Alfa). Langkah selanjutnya adalah menampilkan hasil perhitungan nilai $\mathrm{H}$, $\mathrm{R}$, dan Alfa dalam tabel dan menampilkan grafik hubungan frekuensi dengan koefisien refleksi dan koefisien serap Flowchart dari penelitian ini adalah sebagai berikut :

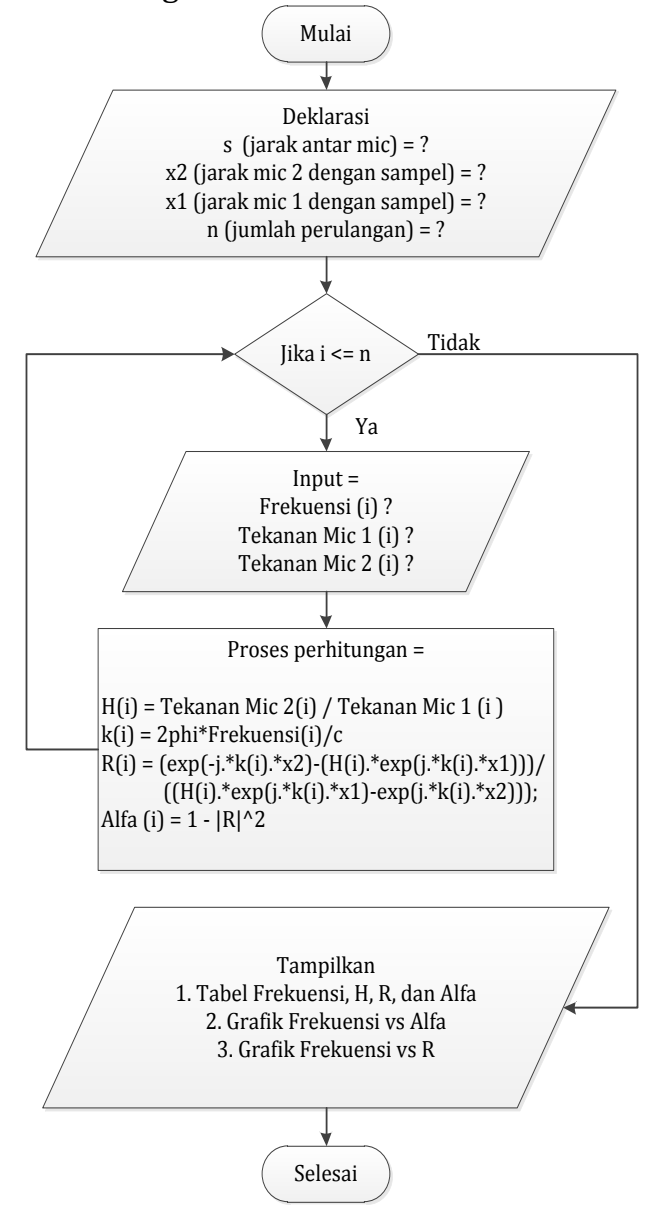

Gambar 2 Flowchart simulasi perhitungan pada Matlab 
POSITRON, Vol. VII, No. 1 (2017), Hal. 08 - 11

http://dx.doi.org/10.26418/positron.v7i1.20828

\section{Hasil dan Pembahasan}

Pada penelitian ini dihasilkan nilai tekanan suara pada microphone 1 (P1) dan microphone 2 (P2) sebagai berikut:

\begin{tabular}{|c|c|c|c|}
\hline No & f & P1 & P2 \\
\hline \multicolumn{4}{|c|}{ 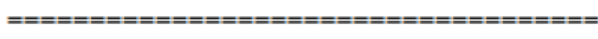 } \\
\hline 1 & 125 & 0.26800000 & 1.88000000 \\
\hline 2 & 250 & 0.33200000 & 2.14000000 \\
\hline 3 & 500 & 1.74000000 & 0.82900000 \\
\hline 4 & 1000 & 0.52600000 & 0.70700000 \\
\hline 5 & 2000 & 0.15500000 & 0.1690000 \\
\hline
\end{tabular}

Gambar 2 Nilai Tekanan pada tiap microphone

Hasil dalam simulasi perhitungan ini dapat dilihat pada gambar-gambar berikut :

\begin{tabular}{|c|c|c|c|c|}
\hline No & f & H & R & Alfa \\
\hline \multicolumn{5}{|c|}{ =" =" } \\
\hline 1 & 125 & 7.014925 & -0.16904819 & -0.942845420 .000000000000000000000 \\
\hline 2 & 250 & 6.445783 & 0.94583624 & 0.789212370 .000000000000000000000 \\
\hline 3 & 500 & 0.476437 & 0.91887427 & 0.688659850 .000000000000000044409 \\
\hline 4 & 1000 & 1.344106 & -0.78192604 & 0.222816660 .00000000000000022204 \\
\hline 5 & 2000 & 1.090323 & 0.69861374 & -0.023877700 .000000000000000022204 \\
\hline
\end{tabular}

Gambar 3 Tabel nilai fungsi transfer, koefisien refleksi dan koefisien serap

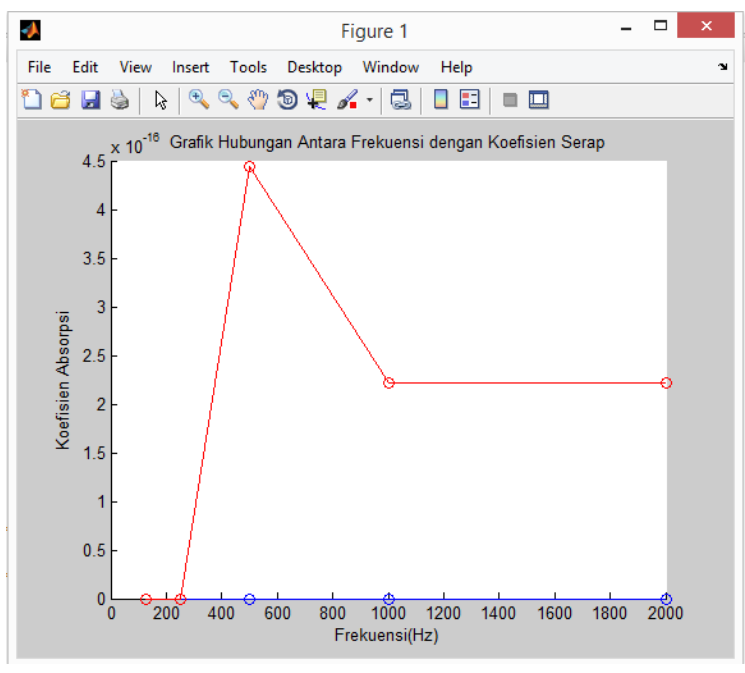

Gambar 4 Grafik hubungan koefisien serap dengan frekuensi
ISSN: 2301-4970 ( print )

ISSN: 2549-936X (online)

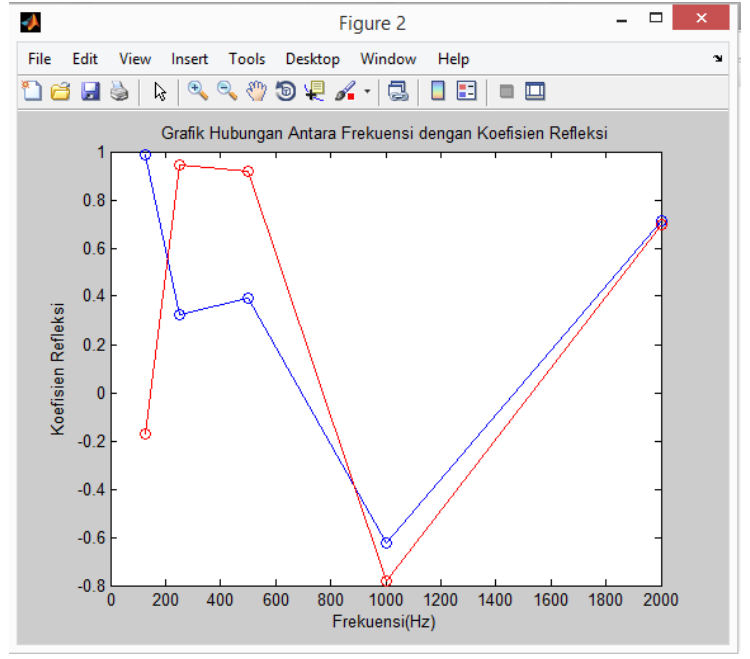

Gambar 6. Grafik hubungan koefisien refleksi dengan frekuensi

Pada gambar 4 dapat diketahui bahwa nilai koefisien serap styrofoam dalam penelitian ini sangat kecil hingga orde -16. Pada gambar 5 adalah grafik hubungan antara frekuensi tiap tekanan terhadap nilai koefisien seraspnya sedangkan pada gambar 6 menunjukkan hubungan antara frekuensi terhadap koefisien refleksinya. Garis merah melambangkan nilai real dari koefisien serap dan koefisien refleksi sedangkan garis biru melambangkan nilai imajiner dari koefisien serap dan koefisien refleksi.

Pada penelitian ini, hasil perhitungan koefisien serap dibandingkan dengan jurnal pembanding. Nilai yang dibandingkan pada penelitian ini adalah nilai koefisien serap saat styrofoam tanpa diberikan lubang yang pada gambar 7dibawah dibawah ini.

\begin{tabular}{ccc}
\hline $\begin{array}{c}\text { Frekuensi } \\
\text { (Hz) }\end{array}$ & \multicolumn{2}{c}{ Styrofoam Tanpa Lubang (STF) } \\
STF 1 & STF2 \\
\hline 125 & 0,294 & 0,293 \\
250 & 0,201 & 0,202 \\
500 & 0,371 & 0,319 \\
1000 & 0,264 & 0,266 \\
2000 & 0,181 & 0,182 \\
\hline
\end{tabular}

Gambar 5 Tabel hasil pengukuran koefisien serap dari jurnal pembanding

Perbedaan nilai koefisien yang terjadi dimungkinkan akibat dari beberapa faktor dibawah ini:

\section{a. Penggunaan sin wave sebagai sound source pada function generator}

Untuk melakukan pengukuran nilai koefisien serap sebaiknya digunakan sound 
source dengan gelombang random noise. Hal ini dikarenakan pada aplikasinya dikehidupan sehari-hari, jenis gelombang yang akan diserap material bermacam-macam sehingga harus digunakan random noise, tidak hanya gelombang sinus.

\section{b. Penggunaan rubber seal pada tabung sebagai tempat freefield microphone}

Pengunaan rubber seal yang sebelumnya dikikir secara manual dikhawatirkan dapat mempengaruhi hasil pengukuran. Pengikikiran rubber seal secara manual dapat membuat kebocoran pada bidang antar tabung dengan freefield microphone sehingga pengukuran tekanan suara pada freefield microphone menjadi terganggu.

\section{c. Kebocoran pada sambungan antar tabung}

Tabung impedansi pada penelitian ini terdiri dari 3 tabung utama, yaitu tabung tempat sound source, tabung tempat pengukuran tekanan suara oleh freefield microphone, dan tabung tempat sampel. Masing-masing tabung akan disambung menggunakan fitting yang terbuat dari acrilic. Untuk menyambungkan fitting digunakan lem dan mur baut. Pengeleman fitting yang tidak pas pada masing-masing tabung dikhawatirkan akan berdampak pada kebocoran suara disambungan antar tabung. Jika ini terjadi maka pengukuran tekanan suara oleh freefield microphone menjadi tidak maksimal.

\section{d. Penempatan freefield microphone pada tabung impedansi}

Penempatan freefield microphone pada tabung impedansi juga mempengaruhi nilai pengukuran tekanan suara. Ketika freefield microphone ditempatkan sejajar dengan permukaan dalam tabung impedansi, nilai tekanan pada freefield microphone yang dekat dengan sampel lebih besar dibandingkan dengan nilai tekanan pada freefield microphone yang dekat dengan sound source. Namun ketika freefield microphone ditempatkan sejajar dengan permukaan luar tabung impedansi, nilai tekanan pada freefield microphone yang dekat dengan sampel lebih kecil dibandingkan dengan nilai tekanan pada freefield microphone yang dekat dengan sound source. Hal ini nantinya akan mempengaruhi nilai dari transfer function sehingga nilai koefisien serapnya tidak mencerminkan nilai sesungguhnya.

\section{Kesimpulan}

Penelitian pembuatan impedance tube dan simulasi pengukuran koefisien serap styrofoam ini menghasilkan kesimpulan sebagai berikut:

1. Pembuatan tabung impedansi telah sesuai dengan standard ISO 10534-2: 1998 dengan detail ukuran sebagai berikut :

- Diameter tabung $=10 \mathrm{~cm}$

- Ketebalan tabung $=5 \% \mathrm{xd}=5 \mathrm{~mm}$

- Jarak antara sumber suara dengan mic terdekat $=70 \mathrm{~cm}$

- Jarak antara sampel dengan mic terdekat $=21 \mathrm{~cm}$

- Jarak antar mic $=9 \mathrm{~cm}$

- $\quad$ Frekuensi batas atas $=1995,2 \mathrm{~Hz}$ batas bawah $=38,22 \mathrm{~Hz}$

2. Faktor yang mempengaruhi perhitungan nilai koefisien serap menggunakan alat impedance tube antara lain : penggunaan sumber suara, penggunaan rubber seal beserta penempatan freefield microphone, dan desain sambungan antar tabung impedansi.

3. Nilai koefisien serap dihasilkan adalah $0,44409 \times 10^{-16}$ pada frekuensi $500 \mathrm{~Hz}$, $0,22204 \times 10^{-16}$ pada frekuensi 1000 dan $2000 \mathrm{~Hz}$.

\section{Daftar Pustaka}

[1] Doelle, L. L. 1993. Akustik Lingkungan. diterjemahkan oleh Lea Prasetyo. Jakarta. Erlangga.

[2] Ljung, Lennart. (2013). Matlab Engineering and Scientific Tool, ReleaseR2012a, Matlab License Number: 77907. Mathwork.

[3] Sabri, 2005, Evaluasi Kinerja Akustik Serat Alam Sebagai Material Alternatif Pengendali Kebisingan, Diakses 4 Februari 2009, dari ITB Central Library, http://digilib.itb.ac.id/gdl.php?mod=brows e\&op=read\&id=jbptitbppgdlsabri $\% 3 \mathrm{Cbr} \%$ 3En-5029\&q=material\%20akustik.

[4] Sriwigiyatno, K. 2006. Analisis Pengaruh Kolom Udara terhadap Nilai Koefisien Serapan Bunyi pada Dinding Partisi Menggunakan Metode Tabung Impedansi Dua Mikrofon. S1 Skripsi Fisika. UNS.

[5] Wolkesson, Martin. 2013. Evaluation of impedance tube methods - A two microphone in-situ method for road surfaces and the three microphone transfer function method for porous materials. Master's Thesis. Chalmers University of Technology. 